\title{
Multiple arterial grafting: The cost of an inconvenience
}

\author{
Joseph Schmoker, MD
}

\author{
From the Division of Cardiothoracic Surgery, University of Vermont Medical Center, Burlington, Vt. \\ Disclosures: Dr Schmoker receives honoraria from Medtronic, Inc. \\ Received for publication Sept 17, 2015; accepted for publication Sept 17, 2015. \\ Address for reprints: Joseph Schmoker, MD, Division of Cardiothoracic Surgery, University of Vermont Medical \\ Center, 111 Colchester Ave, MCHV Campus Fletcher 4, Burlington, VT 05401 (E-mail: Joseph.schmoker@ \\ vtmetnet.org). \\ J Thorac Cardiovasc Surg 2015;150:1546-7 \\ 0022-5223/\$36.00 \\ Copyright (C) 2015 Published by Elsevier Inc. on behalf of The American Association for Thoracic Surgery \\ http://dx.doi.org/10.1016/j.jtcvs.2015.09.064
}

Multiple arterial grafting (MAG) for coronary artery disease is a trending topic, as witnessed by multiple recent publications in this Journal..$^{1-4}$ Accompanying editorials to these articles provide insight into a controversy born seemingly of strong supportive survival data pitted against the unwillingness of most surgeons to adopt this strategy. Indeed, only about $10 \%$ of cardiac surgeons in the United States use MAG. ${ }^{5}$ Of the various reasons given for this reluctance to change practice, the one most readily transparent and interpretable is the argument that conclusive graft patency and patient outcome data are lacking because of fundamental design flaws in observational longitudinal studies. In fact, the majority of studies that promote MAG are retrospective in nature, albeit drawn from large databases that use propensity score matching as a means to equalize patient risk profile. The article by Tranbaugh and colleagues ${ }^{6}$ in this issue of the Journal reports one such study.

Tranbaugh and colleagues ${ }^{6}$ performed propensity matching on almost 5000 patients from a single institution during a 15-year period to compare survival of patients receiving more than 1 arterial graft with those receiving vein grafts as the second-choice conduit after the left internal thoracic artery (LITA). More than 1000 matched pairs were studied, with the primary finding that survival was better in those patients who received more than 1 arterial graft. The study's authors previously reported similar findings in a smaller patient cohort. ${ }^{7}$ The novelty of their current study is the use of the survival curves to estimate the reduction of deaths and the number of additional years of life gained if a policy of expanded MAG were to be adopted in a hypothetical US population sample with a similar risk profile. In this hypothetical model of 200,000 patients, Tranbaugh and colleagues $^{6}$ found that an $80 \%$ rate of MAG could result in 10,000 fewer deaths annually and promote more than 64,000 person-years of life during a 10 -year period.

Although the study only assessed all-cause mortality, it is generally presumed that the contribution from cardiac death through the years is due to graft attrition. The majority of the arterial grafts used as a second conduit in this study were radial arteries. The survival advantage in the radial

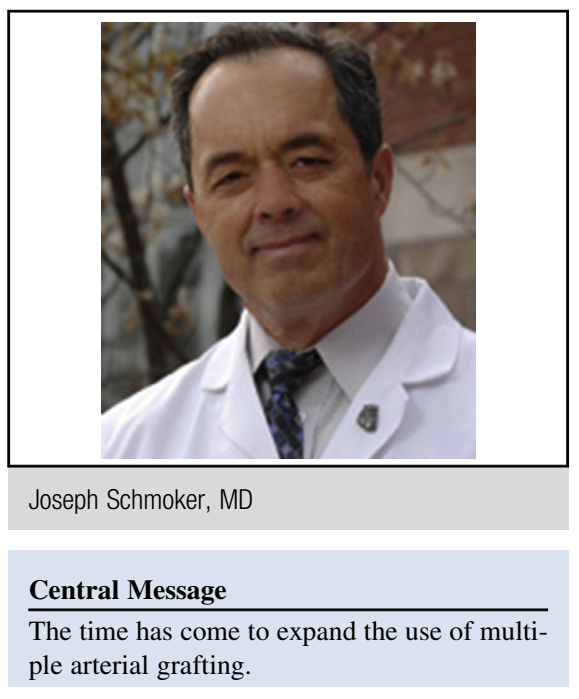

See Article page 1537. artery group was seen early, suggesting that this group already had a patency advantage relative to the vein graft group at 5 years. Although patency was not assessed, a previous study by the same group found that radial artery patency at 5 years was equivalent to LITA patency and meaningfully better than vein graft patency. ${ }^{8}$ Similar findings were not noted in the recent report of 5-year outcomes of a second arterial graft in the Synergy Between Percutaneous Coronary Intervention With TAXUS and Cardiac Surgery Trial and Registry (SYNTAX) study. ${ }^{4}$

A limitation of retrospective studies reporting on graft patency is the inclusion of patients with symptoms only, which underestimates graft attrition rates. Prospective, randomized studies designed to assess angiographic patency in all patients provide further insight. Deb and colleagues, ${ }^{9}$ reporting on the results of the Radial Artery Patency Study (RAPS), found better midterm angiographic patency in radial arteries than in saphenous veins. In a later substudy, this effect appeared only in the population with diabetes. ${ }^{10}$ In the Radial Artery Patency and Clinical Outcomes Trial, another prospective randomized study, angiographic patency in radial arteries and saphenous veins were equivalent at 5 years. ${ }^{11}$ In a meta-analysis of 5 randomized controlled trials of angiographic patency, Cao and colleagues ${ }^{12}$ found that radial artery patency was superior to that of saphenous vein at midterm follow-up (4 years and beyond).

In aggregate, these studies and others weigh favorably in support of the radial artery as a superior conduit to the 
saphenous vein as the second-choice graft for coronary artery bypass grafting. Strong evidentiary support is also given to the use of the right internal thoracic artery as a second conduit, which appears to behave similarly to the radial artery with regard to midterm outcomes. ${ }^{13}$ In the study of Tranbaugh and colleagues, ${ }^{6} 6 \%$ of patients received a right internal thoracic artery in addition to a radial artery, and approximately one-third of patients received more than 2 arterial grafts. It is unclear whether the addition of just 1 additional arterial graft with the LITA will affect survival, although the data of Tranbaugh and colleagues ${ }^{6}$ would suggest so. This becomes important because the reluctance to perform MAG may be due in part to the logistic issues and technical demands related to arterial graft harvesting and use. Bilateral internal thoracic artery harvest is time consuming when performed in skeletonized fashion, which should be done to preserve the surrounding microcirculation and reduce sternal wound complications. ${ }^{3}$ Skeletonized arteries are also somewhat more tedious to work with, which may diminish surgeon enthusiasm for their use. The radial artery is easier to work with, other than requiring additional care with the proximal anastomosis, whether that is to the LITA or the ascending aorta. Radial artery harvest requires a second assistant for concomitant excision with the vein, or an additional time commitment when the 2 are harvested sequentially by a single assistant. Indeed, the downtick in radial artery use by Tranbaugh and colleagues ${ }^{6}$ seen after 1997 was due in part to these logistic issues. The resurgence in use occurred after they discovered the survival impact of MAG on their patients, which made any logistic issue seem trivial. It is their opinion that the stepwise adaptation of adding a radial artery graft in addition to a LITA in selected patients is the most efficient and logical first step in progression to total arterial grafting.

The commodity of time is precious in our profession. Inefficiencies and inconveniences often make long days even longer. As cardiothoracic surgeons, we work to eliminate many of these inconveniences, but eliminating some may have undue costs. Should we pass these costs on to our patients?

\section{References}

1. Buxton BF, Shi WY, Tatoulis J, Fuller JA, Rosalion A, Hayward PA. Total arterial revascularization with internal thoracic and radial artery grafts in triple-vessel coronary artery disease is associated with improved survival. J Thorac Cardiovasc Surg. 2014;148:1238-43; discussion 1243-4.

2. Raza S, Sabik JF III, Masabni K, Aindaran P, Lytle B, Blackstone EH. Surgical revascularization techniques that minimize surgical risk and maximize late survival after coronary artery bypass grafting in patients with diabetes mellitus. J Thorac Cardiovasc Surg. 2014;148:1257-64; discussion 1264-6.

3. Benedetto U, Amrani M, Gaer J, Bahrami T, de Robertis F, Simon AR, et al. The influence of bilateral internal mammary arteries on short- and long-term outcomes: a propensity score matching in accordance with current recommendations. J Thorac Cardiovasc Surg. 2014;148:2699-705.

4. Parasca CA, Head SJ, Mohr FW, Mack MJ, Morice MC, Holmes DR Jr, et al; SYNTAX Investigators. The impact of a second arterial graft on 5-year outcomes after coronary artery bypass grafting in the Synergy Between Percutaneous Coronary Intervention With TAXUS and Cardiac Surgery Trial and Registry. $J$ Thorac Cardiovasc Surg. 2015; 150:597-606.e2.

5. Head SJ, Börgermann J, Osnabrugge RL, Kieser TM, Falk V, Taggart DP, et al. Coronary artery bypass grafting: part 2-optimizing outcomes and future prospects. Eur Heart J. 2013;34:2873-86.

6. Tranbaugh RF, Lucido DJ, Dimitrova KR, Hoffman DM, Geller CM, Dincheva GR, et al. Multiple arterial bypass grafting should be routine. J Thorac Cardiovasc Surg. 2015;150:1537-45.

7. Tranbaugh RF, Dimitrova KR, Friedmann P, Geller CM, Harris LJ, Stelzer P, et al. Radial artery conduits improve long-term survival after coronary artery bypass grafting. Ann Thorac Surg. 2010;90:1165-72.

8. Tranbaugh RF, Dimitrova KR, Friedmann P, Geller CM, Harris LJ, Stelzer P, et al. Coronary artery bypass grafting using the radial artery: clinical outcomes, patency, and need for reintervention. Circulation. 2012;126(11 Suppl 1):S170-5.

9. Deb S, Cohen EA, Singh S, Une D, Laupacis A, Fremes SE, RAPS Investigators. Radial artery and saphenous vein patency more than 5 years after coronary artery bypass surgery: results from RAPS (Radial Artery Patency Study). J Am Coll Cardiol. 2012;60:28-35.

10. Deb S, Singh SK, Moussa F, Tsubota H, Une D, Kiss A, et al; Radial Artery Patency Study Investigators. The long-term impact of diabetes on graft patency after coronary artery bypass grafting surgery: a substudy of the multicenter Radial Artery Patency Study. J Thorac Cardiovasc Surg. 2014;148:1246-53; discussion 1253 .

11. Hayward PAR, Gordon IR, Hare DL, Matalanis G, Horrigan ML, Rosalion A, et al. Comparable patencies of the radial artery and right internal thoracic artery or saphenous vein beyond 5 years: results from the Radial Artery Patency and Clinical Outcomes trial. J Thorac Cardiovasc Surg. 2010;139:60-5; discussion 65-7.

12. Cao C, Manganas C, Horton M, Bannon P, Munkholm-Larsen S, Ang SC, et al. Angiographic outcomes of radial artery versus saphenous vein in coronary artery bypass graft surgery: a meta-analysis of randomized controlled trials. J Thorac Cardiovasc Surg. 2013;146:255-61.

13. Hayward PA, Hare DL, Gordon I, Matalanis G, Buxoton RF. Which arterial conduit? Radial artery versus free right internal thoracic artery: six-year clinical results of a randomized controlled trial. Ann Thorac Surg. 2007;84:493-7; discussion 497. 